\title{
Editor's notes
}

\section{The data is out there - just like the truth!}

Welcome to the first issue of Volume 41 of the IASSIST Quarterly. It has taken extra time for this issue to appear. The cause of this is not that we have been extra lazy. The paradoxical cause is that a great many people have been extra busy. Thanks to the team of people in the editorial group of the IASSIST Quarterly and - not least - the great help from Sonya Betz working as Digital Initiatives Projects Librarian at the University of Alberta Libraries in Canada, the IASSIST Quarterly has now moved to the Open Journal System (OJS) at the University of Alberta. We believe this shift is going to benefit all stakeholders of the IQ. It is mostly the inner workings of the production that has changed. As a potential author you are still very welcome to mail the editor.

The first issue of Volume 41 (2017) at the same time becomes the last issue. In order to get close to the real time we are catching up by jumping three issues. Therefore, this issue is labelled as Vol. 41:14 of 2017. Next issue will be 42:1 of 2018.

The first article concerns data for published articles in journals. The paper 'Journals in Economic Sciences: Paying Lip Service to Reproducible Research?' is by Sven Vlaeminck and Felix Podkrajac. Sven Vlaeminck works in research data management for ZBW - German National Library for Economics / Leibniz Information Centre for Economics in Hamburg, Germany. Felix Podkrajac is an academic subject librarian at the Library and Information System of the Carl von Ossietzky University of Oldenburg. Some economic journals have a 'data availability policy', and Vlaeminck and Podkrajac are presenting a study of the compliance of actual research to such policies. Half a century ago economic journals were mostly theoretical but now most articles are data-based. In their introduction, they present a good overview of literature and, among others, they cite McCullough (2009). I think it is appropriate to repeat part of that citation:

'Replication ensures that the method used to produce the results is known. Whether the results are correct or not is another matter, but unless everyone knows how the results were produced, their correctness cannot be assessed. Replicable research is subject to the scientific principle of verification; non-replicable research cannot be verified.'

Therefore, not only do we need to know the methods, we also need availability and access to the data. Their thorough investigation includes clear definitions and insights into methods and data. Vlaeminck and Podkrajac find that the overall compliance rate is a little below 50 percent and is very variable; some journals - as we would expect when having a data availability policy - reach compliance rates of 100 per cent, while 10 journals have compliance rates below 20 per cent because their data availability policy is voluntary. I don't need to add that the authors have made their replication files available.

The second paper in this IQ issue is titled 'Designing the Cyberinfrastructure for Spatial Data Curation, Visualization, and Sharing' by the authors Yue Li, Nicole Kong, and Stanislav Pejša. All three authors are working at Purdue University Libraries as respectively GIS analyst, assistant professor, and data 
curator. They argue that spatial data is an important component in many studies and has promoted interdisciplinary research development. In their development project at Purdue they have streamlined spatial data curation, visualization and sharing by connecting the institutional research data repository with the library's GIS server set and spatial data portal. The Purdue University Research Repository (PURR) supports data deposits for all Purdue faculty, staff, students and their collaborators. Institutional repositories are becoming more numerous in universities. Because the original dataset owner is often among the first users of the data, a local data repository makes local access an easy solution; however collaboration is important and standards must be in place to gain that benefit. The authors' focus is: 'to increase discoverability beyond the institutional data repository, we expect to ingest the spatial data into our geodata portal'.

The last paper is also addressing data management. The paper 'Research Data Management: A proposed framework to boost research in Higher Educational Institutes' is a collaboration between Bhojaraju Gunjal at Central Library of the National Institute of Technology, Rourkela, Odisha, India, and Panorea Gaitanou of the Department of Archives, Library Science and Museum Studies, Ionian University, Corfu, Greece. They begin with an abstract of Research Data Management (RDM) issues where they promise 'a detailed literature review regarding the RDM aspects adopted in libraries globally'. Their overview provides many links and resources for several aspects of RDM before they describe the implementation of RDM processes at the National Institute of Technology, Rourkela.

Taking good care of data is worth writing articles about, and is also worth writing books about. In this issue we present two book reviews: 'Databrarianship: The Academic Data Librarian in Theory and Practice' by Lynda Kellam and Kristi Thompson is reviewed by Chubing Tripepi of Columbia University, while 'The Data Librarian's Handbook' by Robin Rice and John Southall is reviewed by Ann Glusker of The National Network of Libraries of Medicine.

Submissions of papers for the IASSIST Quarterly are always very welcome. We welcome input from IASSIST conferences or other conferences and workshops, and from local presentations or papers especially written for the IQ. When you are preparing a presentation, give a thought to turning your one-time presentation into a lasting contribution. We permit authors 'deep links' into the IQ as well as deposition of the paper in your local repository. Chairing a conference session with the purpose of aggregating and integrating papers for a special issue IQ is also much appreciated as the information reaches many more people than the session participants, and will be readily available on the IASSIST website at http://www.iassistdata.org.

Authors are very welcome to take a look at the instructions and layout:

http://iassistdata.org/iq/instructions-authors

Authors can also contact me via e-mail: kbr@sam.sdu.dk. Should you be interested in compiling a special issue for the IQ as guest editor(s) I will also be delighted to hear from you.

Karsten Boye Rasmussen - November, 2017 